Katinka M. Smits $\bullet$,

Peter J. K. Kuppen`,

Alexander M. M. Eggermont", Takuya Tamatani ${ }^{\triangle}$,

Masayuki Miyasaka $^{\triangle}$ and

Gert Jan Fleuren ${ }^{\bullet}$

Department of Pathology, University of Leiden $\bullet$, Leiden, Department of Surgery, Rotterdam Cancer Institute", Rotterdam and Department of Immunology, Tokyo Metropolitan Institute of Medical Science $^{\triangle}$, Tokyo

\section{Rat interleukin-2-activated natural killer (A-NK) cell-mediated lysis is determined by the presence of CD18 on A-NK cells and the absence of major histocompatibility complex class I on target cells}

The precise mechanism by which target cells are recognized and subsequently lysed by interleukin-2-activated natural killer (A-NK) cells is poorly understood. In this study the role of major histocompatibility complex (MHC) class I and adhesion molecules in the recognition and lysis of tumor cells was investigated in a syngeneic Wag rat model. Preincubation of tumor cells with $\mathrm{F}\left(\mathrm{ab}^{\prime}\right)_{2}$ fragments of anti-MHC class I monoclonal antibody (mAb) OX18 strongly enhanced the A-NK cell-mediated lysis. Also normal syngeneic cells such as T cells and A-NK cells became highly sensitive for lysis by A-NK cells after preincubation with $\mathrm{mAb}$ OX18. Two other mAb against MHC class I had no effect on lysis of target cells. These data indicate that masking of MHC class I on syngeneic tumor and normal cells by $\mathrm{mAb}$ OX18 is sufficient for A-NK cells to recognize target cells as non-self, resulting in lysis. In addition, we found that the presence of $\mathrm{mAb}$ against the $\beta 2$ (CD18)-integrins blocked the lysis of all tumor cell lines by A-NK cells in ${ }^{51} \mathrm{Cr}$-release assays, also when target cells were preincubated with mAb OX18. Because of the absence of CD18 on most tumor cells we concluded that a CD18-associated integrin on A-NK cells is essential for lysis of target cells. These results show that in this syngeneic rat model $\mathrm{CD} 18$ on A-NK cells together with MHC class I on tumor cells determine A-NK cell-mediated lysis. Furthermore, we hypothesize that the anti-MHC class I OX18 recognizes an epitope on rat MHC class I which is, or is very close to, the restriction element determining A-NK cell-mediated lysis.

\section{Introduction}

NK cells are characterized as large granular lymphocytes which are able to lyse virally infected cells and some tumor cells without prior sensitization. Several molecules have been described to be involved in the binding and recognition of target cells by NK cells. Adhesion molecules have been demonstrated to be responsible for the binding between NK cells and target cells. Especially the CD18associated integrins LFA-1 (CD11a), CR3 (Complement Receptor 3) (CD11b), p150,95 (CD11c) and CD2, present on NK cells and ICAM-1 (CD54) and LFA-3 (CD58), present on target cells are described to be involved in NK cell-mediated lysis of allogeneic target cells [1]. IL-2activated NK (A-NK) cells show an enhanced expression of the $\mathrm{CD} 18$-associated integrins and $\mathrm{CD} 2$, which results in an enhanced binding between the A-NK and target cells [2, 3].

[I 12097]

Correspondence: Katinka M. Smits, Department of Pathology, University of Leiden, P.O. Box 9603, NL-2300 RC Leiden, The Netherlands (Fax: 3171276640 )

\begin{abstract}
Abbreviations: A-NK: IL-2-activated NK ADCC: Antibodydependent cell-mediated cytotoxicity LFA-1: Lymphocyte function-associated antigen-1 ICAM-1: Intercellular adhesion molecule-1.
\end{abstract}

Key words: Natural killer cell / Interleukin-2 / Target cell recognition / Major histocompatibility complex class I / Adhesion molecule

(c) VCH Verlagsgesellschaft mbH, D-69451 Weinheim, 1994
Furthermore, MHC class I on target cells has been described to affect NK cell recognition and/or lethal hit delivery. In a variety of experimental systems NK cells have been shown to recognize and eliminate target cells which fail to express "self" MHC class I ("missing self" hypothesis) [4].

In the present study the "missing self" hypothesis was tested in a syngeneic Wag rat tumor model, using A-NK cells as effector cells and tumor and normal cells as target cells. Furthermore, we investigated the involvement of adhesion molecules in the A-NK cell-mediated lysis of target cells. For this study we used $\mathrm{mAb}$ against several adhesion molecules and $\mathrm{mAb}$ against MHC class I. We demonstrate here that $\mathrm{CD} 18$ plays a major role in the rat A-NK cell-mediated lysis of syngeneic target cells and that masking of MHC class I on target cells by anti-MHC class I $\mathrm{mAb}$ OX18 is sufficient for rat A-NK cells to lyse syngeneic target cells.

\section{Materials and methods}

\subsection{Antibodies}

The anti-rat mAb OX18 [5, 6], U9F4 [7], F16.4.4.11 (F16) [8] (all anti-MHC class I), WT.3 (anti-CD18), WT.1 (antiCD11a, LFA-1), 1A29 (anti-ICAM-1) [9, 10], OX42 (antiCD11b/c) [11], ED7, ED8 (CD11b) [12, 13], and R73 (anti- $\alpha \beta$-T cell receptor) [14] were used in this study. All antibodies were of the IgG1 isotype, except U9F4 and WT.1, which were of the IgG2a subclass. OX18, F16.4.4 and OX42 were purchased from ECACC (Porton Down, 
Salisbury, GB). U9F4 was kindly provided by Dr. F. Thielen (Gaubius Institute, TNO, Leiden, The Netherlands), ED7 and ED8 were kindly provided by Dr. J. G. M. C. Damoiseaux and Dr. C. D. Dijkstra, Vrije Universiteit, Amsterdam, The Netherlands. R73 was a gift from Dr. T. Hünig (Ludwig Maximilians University, Munich, FRG).

\subsection{Production of $F\left(a^{\prime}\right)_{2}$ fragments of $\mathrm{OX} 18$}

$\mathrm{F}\left(\mathrm{ab}^{\prime}\right)_{2}$ fragments of $\mathrm{OX} 18$ were obtained by pepsin digestion of OX 18 at $10 \mathrm{mg} / \mathrm{ml}$ in $0.1 \mathrm{M}$ citrate buffer ( $\mathrm{pH} 4)$ in the presence of pepsin attached to $4 \%$ cross-linked beaded agarose (100 U/10 mg protein) (Sigma, St. Louis, $\mathrm{MO}$ ), for $15 \mathrm{~h}$ at $37^{\circ} \mathrm{C}$. After incubation the sample was centrifuged for $5 \mathrm{~min}$ at $7000 \times \mathrm{g}$ and the supernatant containing the $F\left(a b^{\prime}\right)_{2}$ fragments was separated from the pellet containing the pepsin-agarose beads. The $\mathrm{pH}$ of the supernatant was adjusted to 7 with $3 \mathrm{M}$ Tris- $\mathrm{HCl}$ (pH 8.5). The $\mathrm{F}\left(\mathrm{ab}^{\prime}\right)_{2}$ fragments were separated from intact $\operatorname{IgG}$ by affinity chromatography using a protein $\mathrm{A}$ column. The purity of $F\left(a^{\prime}\right)_{2}$ fragments was determined by SDS-PAGE under non-reducing conditions.

\subsection{Tumor cell lines}

CC531, a Wag rat colon carcinoma [15], and MCR86 and WRM, both Wag rat breast adenocarcinomas, were maintained as adherent cultures in culture medium consisting of RPMI-1640 medium (Gibco, Paisley, Scotland), supplemented with $10 \%$ heat-inactivated FCS (Gibco), 2 mM $\mathrm{L}$-glutamine, $50 \mu \mathrm{g} / \mathrm{ml}$ streptomycin and $50 \mathrm{U} / \mathrm{ml}$ penicillin. L4415, a Wag rat immature T cell leukemia was passaged in vivo through intravenous (in tail vein) inoculation [16]. A large stock was prepared from spleens of tumor-injected animals and stored in liquid nitrogen.

\subsection{Preparation of A-NK cells and T cells}

A-NK cells and T cells were cultured from spleens of Wag rats according to protocols described before $[17,18]$. A-NK cells obtained were $>98 \%$ NKR-P1 (rat NK marker) positive and $<1 \% \mathrm{TcR}$ positive. $\mathrm{T}$ cells were $>98 \% \mathrm{TcR}$ positive.

\subsection{Flow cytometry}

Briefly, tumor cells $\left(5 \times 10^{5}\right)$ were subsequently incubated $\left(30 \mathrm{~min}, 4^{\circ} \mathrm{C}\right)$ with a saturating amount of one of the $\mathrm{mAb}$ and then with a predetermined optimal dilution of a fluorescein isothiocyanate-labeled goat anti-mouse antibody (SBA, Birmingham, AL). Fluorescence analysis was performed using a FACScan flow cytometer (Becton Dickinson, Mountain View, CA).

\section{$2.6{ }^{51} \mathrm{Cr}$-release assay}

Four-hour ${ }^{51} \mathrm{Cr}$-release assays were performed essentially as described earlier [17]. Target cells $\left(0.5 \times 10^{6}\right)$ were incubated with either $1 \mu \mathrm{g}$ OX $18 \mathrm{mAb}, \mathrm{F}\left(\mathrm{ab}^{\prime}\right)_{2}$ fragments of OX18, U9F4 mAb, F16 mAb, or no $\mathrm{mAb}$ (as control) for $30 \mathrm{~min}$ at $4^{\circ} \mathrm{C}$, before labeling with ${ }^{51} \mathrm{Cr}$. Where indicated, one of the $\mathrm{mAb}$ against adhesion molecules were present during the assay (final concentration $5 \mu \mathrm{g} / \mathrm{ml}$ ). None of the $\mathrm{mAb}$ affected the spontaneous release of the ${ }^{51} \mathrm{Cr}$-labeled target cells. For CC531 and MCR86 an incubation period of $19 \mathrm{~h}$ was used [17]. Representative data out of at least three experiments are shown as percentage of specific ${ }^{51} \mathrm{Cr}$ release which are means of triplicate wells.

\section{Results}

\subsection{Expression of surface antigens by tumor cells and normal cells}

The expression of the surface antigens CD18, LFA-1, ICAM-1 and MHC class I on tumor cells and normal cells was measured by flow cytometry. It is shown that the tumor cell lines CC531, MCR86, WRM, and L4415 expressed ICAM-1 and that L4415 additionally expressed CD18 and LFA-1 (Fig. 1). A-NK cells were shown to express MHC

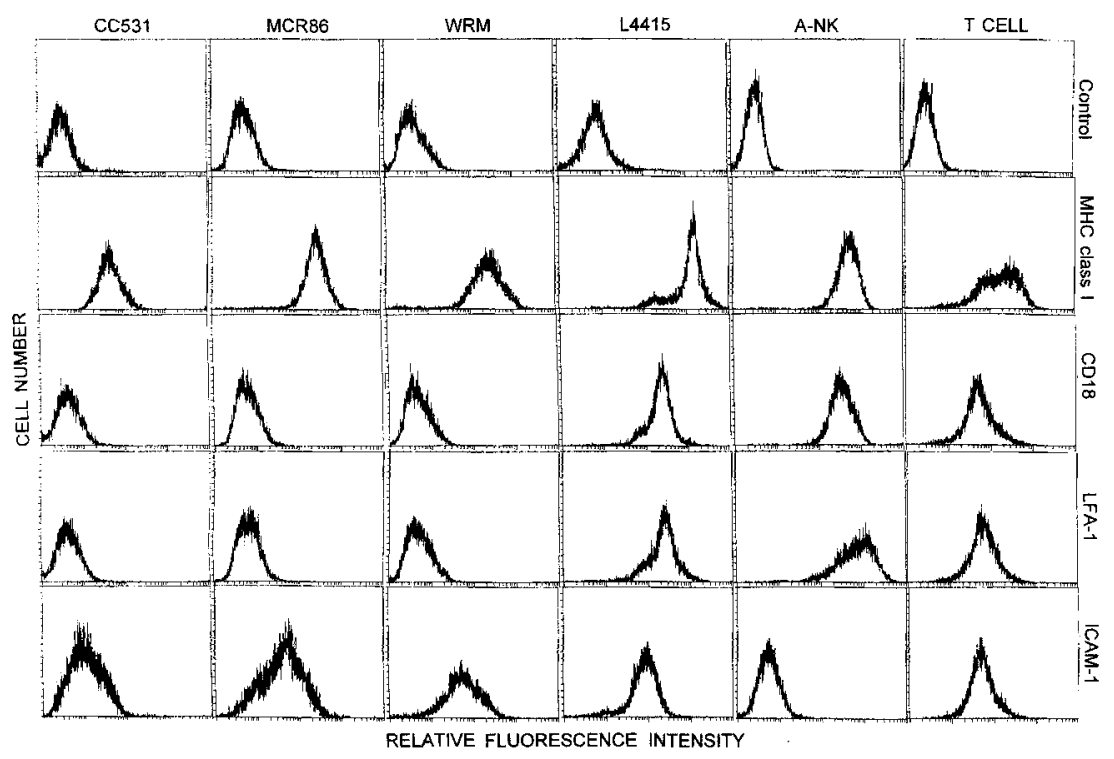

Figure 1. Expression of MHC class I and adhesion molecules by tumor cells and normal cells. Tumor cell lines CC531, MCR86, WRM, L4415 and normal cells (A-NK cells and T cells) were stained by indirect immunofluorescence with the following mAb: OX18 (anti-MHC class I); WT.3 (anti-CD18); WT.1 (anti-LFA-1); 1A29 (anti-ICAM-1), and were subsequently analyzed for fluorescence intensity by flow cytometry as described in Sect. 2.5. As a control, cells were incubated with goat anti-mouse-FITC only. 
class I, CD18 and LFA-1, but not ICAM-1. T cells expressed all markers shown: MHC class I, CD18, LFA-1 and ICAM-1. Furthermore, we found that A-NK cells did not express other CD18-associated CD11-subunits (CD11b/c) than LFA-1 (CD11a) (data not shown).

\subsection{Participation of adhesion molecules in the cytolysis of tumor cells by $A-N K$ cells}

To assess the role of CD18-associated integrins in A-NK cell-mediated lysis, we evaluated the effect of anti-CD18 (WT.3) on lysis of the tumor cell lines in ${ }^{51} \mathrm{Cr}$-release assays. In the presence of this $\mathrm{mAb}$ against $\mathrm{CD} 18, \mathrm{~A}-\mathrm{NK}$ cellmediated lysis of CC531 and L4415 was completely inhibited and the lysis of MCR86 and WRM was inhibited by more than $60 \%$ (Table 1). The involvement of CD18associated CD11-subunits $(\mathrm{CD} 11 \mathrm{a} / \mathrm{b} / \mathrm{c})$ in $\mathrm{A}-\mathrm{NK}$ cellmediated lysis was investigated with $\mathrm{mAb}$ against CD11a (WT.1), CD11b/c (OX42) and CD11b (ED7 and ED8). Table 1 shows that the presence of anti-CD11a or CD11b/c did not have any effect on the A-NK cell-mediated lysis of CC531. Also mAb against the counterpart of CD11a/c integrins ICAM-1 (1A29) had no effect on the lysis of the tumor cells by A-NK cells.

Table 1. Lysis of tumor cells by A-NK cells in presence of mAb against adhesion molecules ${ }^{\text {a) }}$

\begin{tabular}{lrrrrc}
\hline $\begin{array}{l}\text { Target } \\
\text { cells }\end{array}$ & \multicolumn{5}{c}{ \% specific ${ }^{51}$ Cr release } \\
& Control & LFA-1 & CD18 & ICAM-1 & CD11b/c \\
\hline CC531 & 22 & 22 & 0 & 23 & 24 \\
MCR86 & 19 & 19 & 4 & 20 & n.t. ${ }^{\text {b) }}$ \\
WRM & 14 & 16 & 5 & 13 & n.t. \\
L4415 & 5 & 5 & 0 & 4 & n.t. \\
\hline
\end{tabular}

a) A-NK cells were incubated with tumor cells in the presence of mAb against LFA-1 (WT.1), CD18 (WT.3), ICAM-1 (1A29), $\mathrm{CD} 11 \mathrm{~b} / \mathrm{c}(\mathrm{OX} 42)$, or CD11b (ED7, ED8) in a ${ }^{51} \mathrm{Cr}$-release assay as described in Sect. 2.6. As control, the assay was performed without $\mathrm{mAb}$.

b) n.t. = not tested.

\subsection{Involvement of MHC class I in the tumor cell lysis by A-NK cells}

To investigate the role of MHC class I in A-NK cellmediated lysis, tumor cells were preincubated with $\mathrm{mAb}$ against MHC class I (OX18) and used as target cells in a ${ }^{51} \mathrm{Cr}$-release assay. Fig. 2 shows that the lysis of all OX18preincubated tumor cells was highly increased in comparison with the lysis of untreated tumor cells. Furthermore, addition of anti-CD18 mAb WT.3 completely blocked the enhanced lysis of the OX18-preincubated tumor cells. To exclude that the enhancement of lysis was caused by ADCC we produced $F\left(\mathrm{ab}^{\prime}\right)_{2}$ fragments of OX18. Fig. $3 \mathrm{~A}$ shows one band at $150 \mathrm{kDa}$ in the lane of total mAb OX18. In the $\mathrm{F}\left(\mathrm{ab}^{\prime}\right)_{2}$ lane a band of $100 \mathrm{kDa}$, but no band at $150 \mathrm{kDa}$ could be detected, showing that the $\mathrm{F}\left(\mathrm{ab}^{\prime}\right)_{2}$ fragments were free from total $\mathrm{mAb}$. Subsequently, CC531 was preincubated with $\mathrm{F}\left(\mathrm{ab}^{\prime}\right)_{2}$ fragments of OX18 and used as target cells for A-NK cell-mediated lysis. The $F\left(a b^{\prime}\right)_{2}$ fragments
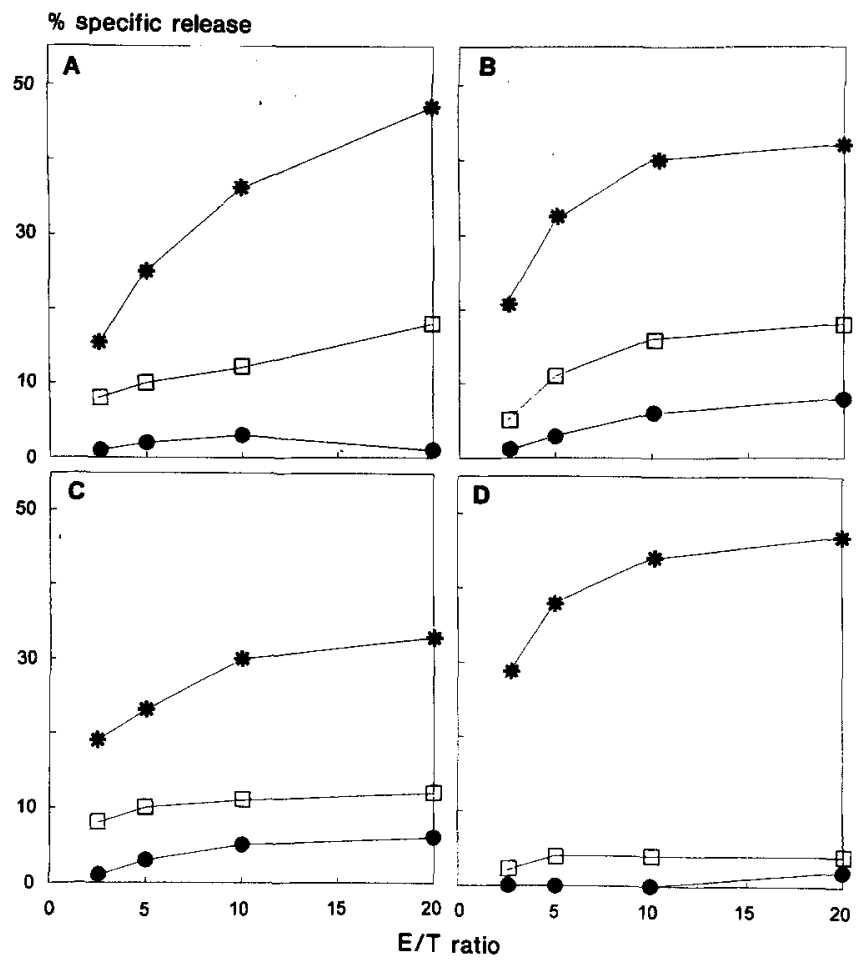

Figure 2. Effect of anti-CD18 mAb WT.3 and anti-MHC class I mAb OX18 on A-NK cell-mediated lysis of tumor cells. Target cells were tumor cell lines CC531 (A), MCR86 (B),WRM (C) and L4415 (D) without antibody ( $\square$ ) or preincubated with mAb OX18 and then tested in the absence $(*)$ or the presence $(\bullet)$ of mAb WT. 3 in a ${ }^{51} \mathrm{Cr}$-release assay as described in Sect. 2.6.

A

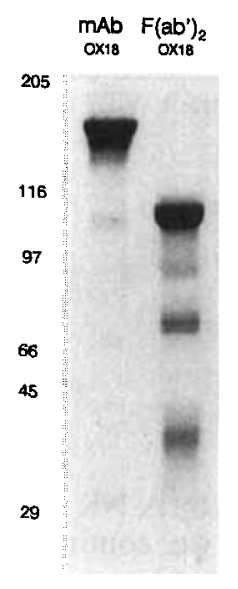

B $\%$ specific release

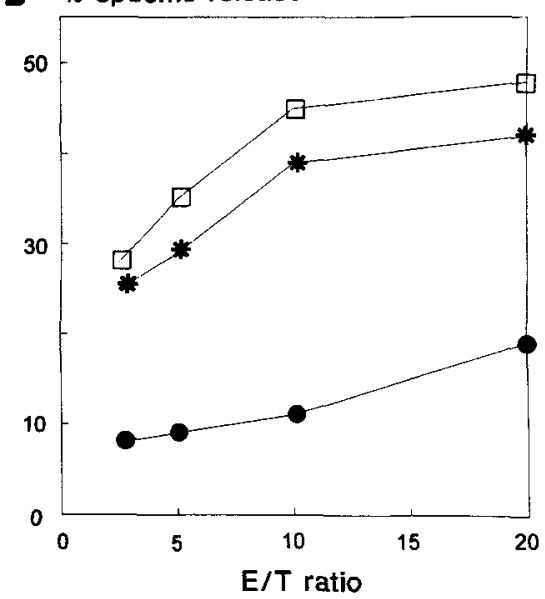

Figure 3, A-NK cell-mediated lysis of CC531 preincubated with mAb OX18 or $F\left(a b^{\prime}\right)_{2}$ fragments of OX18. (A) SDS-PAGE of $\mathrm{F}\left(\mathrm{ab}^{\prime}\right)_{2}$ fragments of OX18 under non-reducing conditions. Molecular weight of the bands is indicated in $\mathrm{kDa}$. (B) CC531 target cells were preincubated with PBS $(\bullet), \operatorname{mAb}$ OX18 $(\square)$ or $\mathrm{F}\left(\mathrm{ab}^{\prime}\right)_{2}$ fragments of OX18 $(*)$.

were shown to be as effective as intact $\mathrm{mAb}$ in enhancing the lysis of CC531 by A-NK cells (Fig. 3B). Therefore, ADCC could be excluded. 


\subsection{Lysis of syngeneic normal cells by A-NK cells}

Next, we investigated whether syngeneic normal cells could also be lysed by A-NK cells when MHC class I on these normal cells was masked by the anti-MHC class I mAb OX18. As syngeneic normal target cells we used A-NK and Tcells. No lysis of untreated A-NK cells and Tcells was detected (Fig. 4). However, when these cells were preincubated with the anti-MHC class I OX18 $60 \%$ of the T cells were lysed (E/T ratio 20$)$ and $35 \%$ of the A-NK cells were lysed (E/T ratio 20 ) by A-NK cells. Anti-CD18 mAb WT.3 again completely blocked the lysis of these OX18-preincubated target cells.

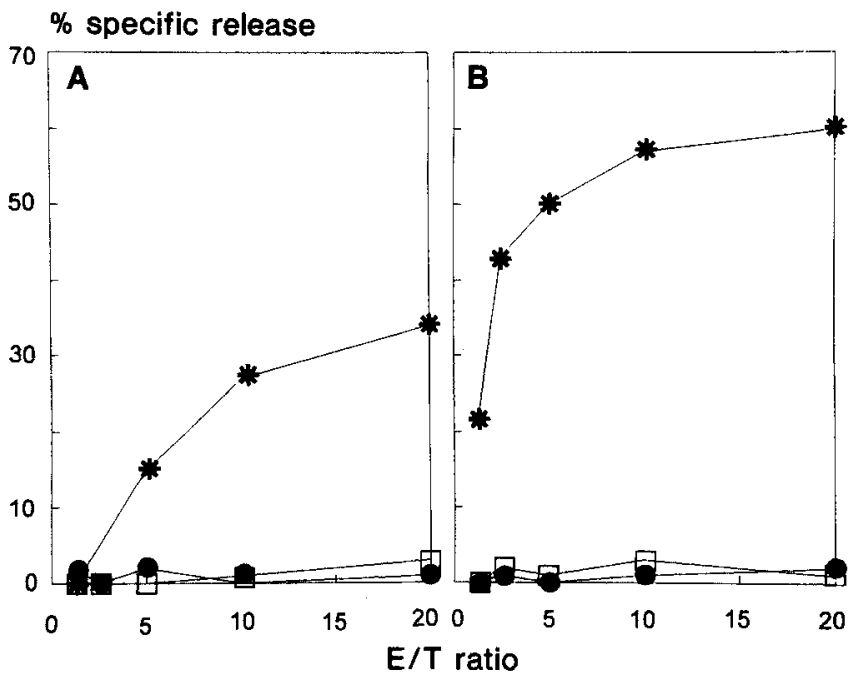

Figure 4. Effect of anti-CD18 mAb WT.3 and anti-MHC class I mAb OX18 on A-NK cell-mediated lysis of normal cells. A-NK cells were incubated either with normal target cells ( $A$ : A-NK cells; B: T cells $(\square)$ or with normal target cells preincubated with $\mathrm{mAb}$ OX18 in the absence $\left(^{*}\right)$ or in the presence of mAb WT.3 (-) in a ${ }^{51} \mathrm{Cr}$-release assay as described in Sect. 2.6.

\section{Discussion}

The mechanism of target cell recognition by A-NK cells is still poorly understood. In this study we confirm the "missing self" hypothesis proposed by Ljunggren and Kärre [4] in a syngeneic rat model. We demonstrated that tumor cells are lysed by A-NK cells if MHC class I on the tumor cells is masked by the anti-MHC class I mAb OX18. This effect of anti-MHC class I mAb on A-NK cell-mediated lysis of tumor cells has also previously been shown in mouse and human models [19-22]. In addition, we show in this study that A-NK cells were able to kill not only tumor cells but also syngeneic normal cells when the "self" MHC class I molecules were masked by anti-MHC class I OX18. Apparently, A-NK cells are triggered for lysis when cells fail to express "self" MHC class I, as predicted by the effector inhibition model [4]. A prerequisite is that binding of these target cells must be possible via a CD18-associated integrin on A-NK cells.
In our blocking experiments we showed that $\mathrm{CD} 18$ was involved in A-NK-mediated lysis but we could not show ICAM-1 or a CD18-associated CD11 to be involved. The $\mathrm{mAb}$ we used have already been described to block other specific cellular functions. The anti-LFA-1 mAb WT.1 and the anti-ICAM-1 mAb 1A29 blocked T cell proliferation and T cell-mediated lysis [10, 23]. Anti-CD11b/c (ED7, ED8) were able to inhibit macrophage recruitment [13]. In agreement with our observations Beun et al. did not observe blocking of non-specific T cell-mediated lysis of tumor cells by these mAb [24]. Therefore, these results might suggest that in the rat, LFA-1 and its ligand ICAM-1 are not involved in the process of target cell lysis by A-NK cells. Alternatively, it can not be excluded that the $\mathrm{mAb}$ against LFA-1 and ICAM-1 we used did not block the functional binding site of LFA-1 and ICAM- 1 on A-NK and tumor cells. The latter possibility is more likely because in the human and mouse system the involvement of these adhesion molecules in A-NK-mediated lysis has been shown using antibodies against LFA-1 and ICAM-1 [25, 26]. Other $m A b$ against rat LFA-1 and ICAM-1, recognizing other epitopes on these adhesion molecules have to be developed to investigate whether these adhesion molecules are really involved in A-NK-mediated lysis in the rat.

The involvement of RT1 (MHC class I in the rat) in A-NK cell-mediated lysis was shown in an allogeneic rat model by Vaage et al. [27, 28]. They showed that the RT1.C region has a predominant role in determining target cell susceptibility for rat NK alloreactivity. In our syngeneic model we show that masking of RT1 by intact IgG or $F\left(a b^{\prime}\right)_{2}$ fragments of OX18 on target cells enhances rat A-NK cell-mediated lysis. MAb OX18 has been described to bind to determinants of RT1.A antigens [5], but also of the RT1.C antigens [6]. Apparently, by masking the RT1.A/C antigens on target cells the A-NK cells were not able to recognize the target cells as self, resulting in lysis of the target cell. Other anti-MHC class I mAb U9F 4 and F16 did not increase the A-NK cell-mediated lysis of tumor target cells. Therefore, we hypothesize that the mAb OX18 recognizes an epitope on rat histocompatibility RT1 which is, or is very close to, the restriction element which determines A-NK cell-mediated lysis. This restriction element could be RT1.A or RT1.C, but the studies described by Vaage et al. in an allogeneic rat model suggest that it is RT1.C [28]. Further studies, focussed on these RT1-genes, might solve the question which RT1-genes contain the restriction element for A-NK cell-mediated lysis in the rat. This syngeneic rat model and the A-NK-lysis modulating effect of the anti-MHC class I mAb OX18 presented here may be very useful in unravelling the precise mechanism of target recognition by A-NK cells.

We thank Dr. A. Gorter and Dr. J. van Dijk for helpful discussions and $S$. Lazeroms, and J. van Eendenburg for excellent technical assistance. Furthermore, we thank the following persons for their gift of tumor cell lines: Dr. T. Kloosterman, Erasmus University, Rotterdam (L4415), TNO, Rijswijk, The Netherlands (MCR86) and Dr. J. H. van Dierendonck, Dept. of Pathology, University of Leiden, Leiden, The Netherlands (WRM).

Received June 14, 1993; in revised form October 4, 1993; accepted October 5, 1993. 


\section{References}

1 O'Shea, J. and Ortaldo, J. R., in Lewis, L. E. and McGee, J. O. D. (Eds.), The natural immune system. The natural killer cell, Oxford University Press, Oxford 1992, p. 2.

2 Melder, R. J., Walker, E., Herberman, R. B. and Whiteside, T. L., Cell. Immunol. 1991. 132: 177.

3 Timonen, T., Gahmberg, C. G. and Patarroyo, M., Int. J. Cancer 1990. 46: 1035.

4 Ljunggren, H.-G. and Kärre, K., Immunol. Today 1990. 11: 237.

5 Fukumoto, T., McMaster, W. R. and Williams, A. F., Eur. J. Immunol. 1982. 12: 237.

6 Parker, K. E., Carter, C. A. and Fabre, J. W., Immunogenetics 1990. 31: 211.

7 Stet, R. J. M., Zantema, A., Van Laar, T., de Waal, R. M. W., Vaessen, L. M. B. and Rozing, J., Transplant. Proc. 1987. 19: 3004.

8 Hart, D. N. J. and Fabre, J.W., Transplantation 1981. 31: 318.

9 Tamatani, T. and Miyasaka, M., Int. Immunol. 1990. 2: 165.

10 Tamatani, T., Kotani, M. and Miyasaka, M., Eur. J. Immunol. 1991. 21: 627.

11 Robinson, A. P., White, T. M. and Mason, D. W., Immunology 1986. 57: 239.

12 Damoiseaux, J. G. M. C., Döpp, E. A., Neefjes, J. J., Beelen, R. H. J. and Dijkstra, C. D., J. Leukocyte Biol. 1989. 46: 556.

13 Huitinga, I., Damoiseaux, J. G. M. C., Döpp, E. A. and Dijkstra, C. D., Eur. J. Immunol. 1993. 23: 709.

14 Hünig, T., Wallny, H. J., Hartley, J. K., Lawetzky, A. and Tiefenthaler, G., J. Exp. Med. 1989. 169: 73.

15 Marquet, R. L., Westbroek, D. L. and Jeekel, J., Int. J. Cancer 1984. 33: 689.
16 Kloosterman, T. C., Tielemans, M. J. C., Martens, A. C. M., Hoogerbrugge, M., van Bekkum, D. W. and Hagenbeek, A., Leukemia 1992. 6: 1161.

17 Kuppen, P. J. K., Eggermont, A. M. M., Smits, K. M., van Eendenburg, J. D. H, Lazeroms, S. P. G., van der Velde, C. J. H. and Fleuren, G. J., Cancer Immunol. Immunother. 1993. 36: 403.

18 Beun, G. D. M., van Eendenburg, J. D. H., Corver, W. E., Van de Velde, C. J. H. and Fleuren, G. J., J. Immunother. 1992. 11: 238.

19 Lobo, P. I. and Spencer, C. E., J. Clin. Invest. 1989. 83: 278.

20 Sturmhöfel, K. and Hämmerling, G. J., Eur. J. Immunol. 1990. 20: 171 .

21 Maio, M., Altomonte, M.,Tatake, R., Zeff, R. A. and Ferrone, S., J. Clin. Invest. 1991. 88: 282.

22 Kaufman, D. S., Schoon, R. A. and Leibson, P. J., J. Immunol. 1993. 150: 1429.

23 Tamatani, T., Kotani, M., Tanaka, T. and Miyasaka, M., Eur. J. Immunol. 1991. 21: 855.

24 Beun, G. D. M., Gorter, A., Nooyen, Y., Van de Velde, C. J. H. and Fleuren, G. J., J. Immunol. 1993. 150: 2305.

25 Hart, M. K., Kornblutch, J., Main, E. K., Spear, B.T., Taylor, J. and Wilson, D. B., Cell. Immunol. 1987. 109: 306.

26 Timonen, T., Patarroyo, M. and Gahmberg, C. G., J. Immunol. 1988. 141: 1041.

27 Vaage, J.T., Dissen, E., Ager, A., Fossum, S. and Rolstad, B., Eur. J. Immunol. 1991. 21: 2167.

28 Vaage, J. T., Løvik, G., Naper, C., Hedrich, H. J., Wonigeit, K. and Rolstad, B., Transplant. Proc., 1993, in press. 